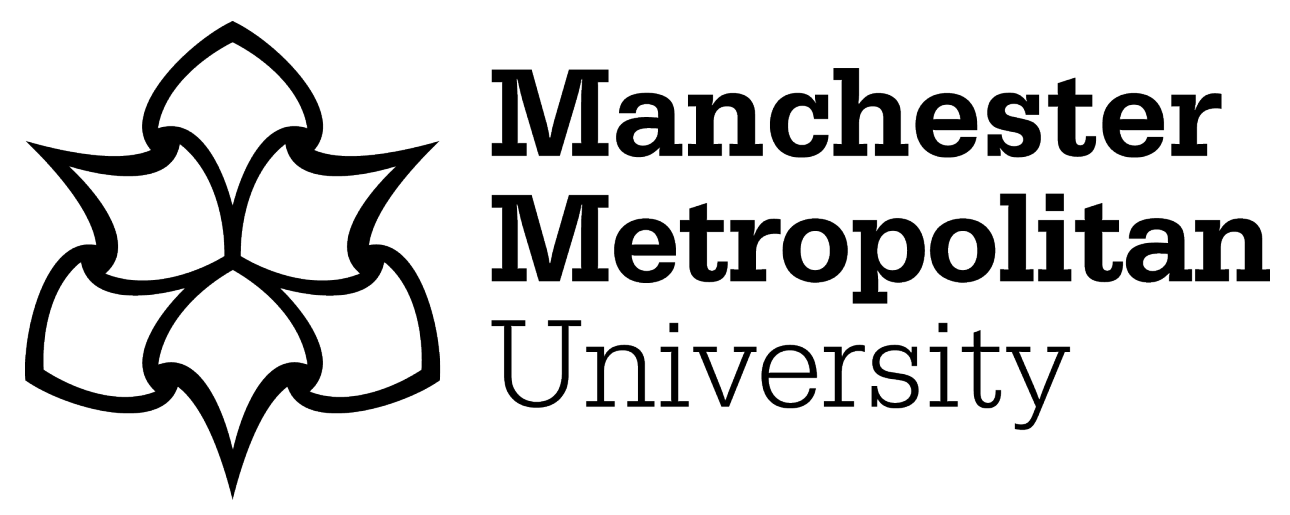

Akram, Sadiya and Hogan, A (2015) On reflexivity and the conduct of the self in everyday life: reflections on Bourdieu and Archer. The British Journal of Sociology, 66 (4). pp. 605-625. ISSN 0007-1315

Downloaded from: https://e-space.mmu.ac.uk/621328/

Version: Accepted Version

Publisher: Wiley

DOI: https://doi.org/10.1111/1468-4446.12150

Please cite the published version 
*Accepted in British Journal of Sociology

\title{
ON REFLEXIVITY AND THE CONDUCT OF THE SELF IN EVERYDAY LIFE: REFLECTIONS ON BOURDIEU AND ARCHER
}

\author{
Sadiya Akram (lead author) \\ IGPA, University of Canberra \\ sadiya.akram@canberra.edu.au \\ Anthony Hogan \\ IGPA, University of Canberra \\ anthony.hogan@canberra.edu.au
}

Word count: 9,142

Date of submission: 05.01 .15 


\title{
ON REFLEXIVITY AND THE CONDUCT OF THE SELF IN EVERYDAY LIFE: REFLECTIONS ON BOURDIEU AND ARCHER
}

\begin{abstract}
This article provides a critique of the concept of reflexivity in social theory today and argues against the tendency to define agency exclusively in terms of reflexivity. Margaret Archer, in particular, is highlighted as a key proponent of this thesis. Archer argues that late modernity is characterised by reflexivity but, in our view, this position neglects the impact of more enduring aspects of agency, such as the routinisation of social life and the role of the takenfor-granted. These concepts were pivotal to Bourdieu and Giddens' theorisation of everyday life and action and to Foucault's understanding of technologies of the self. We offer Bourdieu's habitus as a more nuanced approach to theorising agency, and provide an alternative account of reflexivity. Whilst accepting that reflexivity is a core aspect of agency, we argue that it operates to a backdrop of the routinisation of social life and operates from within and not outside of habitus. We highlight the role of the breach in reflexivity, suggesting that it opens up a critical window for agents to initiate change. The article suggests caution in over-ascribing reflexivity to agency, instead arguing that achieving reflexivity and change is a difficult and fraught process, which has emotional and moral consequences. The effect of this is that people often prefer the status quo, rather than to risk change and uncertainty.
\end{abstract}

Keywords: Reflexivity, routinisation, everyday life, habitus, breach, Archer, Bourdieu 


\section{Introduction}

In this paper we examine what we consider to be a number of significant limitations with Margaret Archer's conceptualistion of agency, as developed in her morphogenetic approach $(1995,2000,2003,2007,2010 a, 2010 b, 2012)$. Archer's theory proposes a seismic shift in how people form and conduct themselves in everyday life, a process that would result in the realisation of extremely high levels of ethical autonomy. If substantiated, Archer's thesis takes the understanding of the formation of agency well beyond existing sociological understandings about ontological security and the routinisation of social life (Giddens 1984, 1991). It would similarly displace Bourdieu's (1977) notion of the habitus as passé, which Archer sees as not being a feature of our current epoch. As such, Archer's perspective is worthy of serious consideration if only because such a position would displace much of what is already known in sociology and social psychology with regards to how people form, understand and manage themselves in everyday life. Our key concern is that Archer over-emphasises reflexivity in her concept of agency to the extent that a) agency is elided with reflexivity, and b) this privileging of reflexivity means that agents are not sufficiently affected by the social, despite her presenting her thesis as a dialectical one where the social is integral to the analysis. In our view, Archer's account acknowledges social structure, but it does so in a very partial way, which ends up privileging agency. Further, her account of agency denies the routine aspects of social life, and singles out the role of habit, in particular, for critique whilst describing it as a redundant concept. We question this, and defend the role of habitus and habit, as well as that of the pre-conscious for establishing ontological security in agency. These latter concepts, in our view, help us to explain how the social 
gets in and why it is difficult, but not impossible to change our practices, and why we do not necessarily have complete control over this process. We progress our consideration of Archer's thesis in four ways:

First, we begin by providing a review and critique of Archer's understanding of agency and reflexivity and bring forth arguments that suggest the approach is partial in its conception of agency. Second, we explore routinisation of social life through Bourdieu's habitus, Giddens' understanding of the taken-for-granted and Foucault's technologies of the self. Third, we highlight the importance of a sociology of the breach when thinking about reflexivity, and show how Giddens and Bourdieu theorise breach and incorporate reflexivity into this process. The final section ends with an illustration of the breach through two case studies: feminist consciousness raising and deafness.

\section{Archer on agency and reflexivity}

Archer's conception of agency is developed within a dialectical approach to the structure and agency problem, i.e. a position that highlights the independent and interactive relationship between structure and agency (Archer, 1995). This position is defended against overly structuralist and subjectivist positions, which emphasise either the former or the latter to the neglect of the other. The role of social structure in society then is integral to Archer's theorization of how society functions, yet for this to be the case, the characteristics of agency must be receptive to social structural influence, which we question in Archer's work. 
For Archer, reflexivity is progressively replacing routine action in late modernity, particularly in more advanced societies. She defines reflexivity as: 'the regular exercise of the mental ability, shared by all normal people, to consider themselves in relation to their (social) contexts and vice versa' (2012: 1). This increase in reflexivity derives from the absence of social guidelines indicating what to do in novel situations, meaning that individuals are increasingly asked to be reflexive in their lives, where once they could follow social rules and norms. Increases in reflexivity in society mirror a transition from a morphostatic (stability and reproduction) to a morphogenetic society (constant change) (Archer: 1995). Archer defines her understanding of reflexivity against that advocated by proponents of the reflexive modernisation thesis (Beck 1992; Giddens 1991) leading her to make a distinction between universal and extended reflexivity. The former refers to her understanding of reflexivity, and defines it as a characteristic of agency, whilst the latter is advocated by Giddens (1991) and Beck (1992), and is a feature of the epoch in which we find ourselves. Reflexivity is also linked to our emotional commitments, our ultimate concerns; all of which help to sustain something called the 'internal conversation' within agents (Archer 2007). The internal conversation reflects the ongoing conversations in agents about who they are and how they see their lives progressing.

For Archer (1995) reflexivity emerges from a new social and cultural order which creates novel situational contexts that confront agents, and which they must negotiate. In such a scenario, agents are said to draw upon their 'socially dependent, but nonetheless personal powers' of reflexivity to define their course(s) of action (2012: p.1). From this perspective, reflexivity is not necessarily positive, because it can also have negative outcomes: some will pursue what they care about most, others will think they are taking 
the best course, but may end up pursuing routes where negative outcomes rebound upon them. On this account, not all reflexivity will be successful, but all, crucially, are trying to be reflexive.

Archer's research leads her to identify different modes of reflexivity. In Making Our Way Through the World (2007) Archer argues that there is movement between modes of reflexivity, but her most recent research suggests that there is a dominant mode of reflexivity. As can be seen below, all modes of reflexivity are dependent upon her notion of the internal conversation. She identifies the following four modes of reflexivity:

- Communicative reflexivity (internal conversations need to be confirmed and completed by others before they lead to action)

- Autonomous reflexivity (internal conversations are self-contained, leading directly to action)

- Meta-reflexivity (internal conversations critically evaluate previous inner dialogues and are critical about effective action in society)

- Fractured reflexivity (internal conversations cannot lead to purposeful courses of action, but intensify personal distress and disorientation resulting in expressive action (Archer 2012: 13).

It is not disputed that reflexivity is important as agents must engage with their own concerns and negotiate the best course of action for themselves. However, the literature holds that it is just one characteristic amongst others (reactivity, avoidance of the breach, decision-making, and habit, to name a few) on a spectrum of agency that exists against a backdrop of the routinisation of social life. Like Archer, we accept that there must be some interplay between changes in society and reflexivity, but this does not mean that identity and agency become a blank canvas. We argue that reflexivity is heightened in 
periods of breach that disturb the durable routines of everyday life. In this article, we highlight different types of breaches (crises) to illustrate the relationship between breach, reflexivity and the processes of change therein.

\section{Archer on Bourdieu}

Archer's rejection of Bourdieu's concept of habitus drives to the heart of the structure and agency problem, in that it is a question about social integration, or of the influences of the social order upon agency. Archer agrees with this point and argues that this debate stems from whether the social should be located 'fully within agents or entirely outside them' (2012: 49).

For Archer, Bourdieu is ultimately problematic on two counts: first, she argues, the world has changed and is unlike the world in which Bourdieu was living and writing, so his approach is described as being historically specific. Second, she argues, a notion of reflexivity is contrary to Bourdieu's notion of practice, which emphasises that all action is 'in situ', and the focus is upon knowing how, not knowing what - or why. It follows, she argues, that the subject is incapable of such reflexivity (2012: 75).

Archer's work raises the idea that individuals actively think about who they are (in the sense of personal and social identity) and modify their identity in the course of everyday being. But what does it mean to argue that agents regularly re-think and evaluate their

everyday being? What kinds of circumstances or frames of reference would be necessary to bring on such a form of reflexivity, and would it be practical to do so? Central to such 
a practice of the self, moreover, is a deep awareness of who one is, how one became who they are and the benefits and motivations of pursuing such new performative aspects of identity. We contend that Archer's position is evidently problematic. It skates over the top of the very basics of how a person becomes who they are and how they maintain and sustain themselves in daily interactions.

Rather we will argue, drawing as we will on a diverse literature, that the habitus is written deeply within us by multiple, layered, intersecting and at times conflicting social processes. As such, the persons who we are are formed within it, shaped and legitimated (and challenged and at times undone) by it.

\section{Bourdieu, habitus and the living of the taken-for-granted}

For Bourdieu, it is within the habitus that one deeply learns the doxic nature of one's society - the deeply held and practiced, but perhaps not discussed, taken-for-granted which is made up of the so many givens in any particular society (1977). Doxa, in his view, is the experience by which the 'natural and social world appears as self evident' (1977: 164). Akram $(2012,2014)$ argues that such beliefs are deep and enduring because they operate at a pre-conscious level. Bourdieu argues that our feel for the game of living life, the understanding of how to behave and interact on a daily basis as human beings is shaped by the habitus:

[T]hat system of durable, transposable dispositions, structured structures predisposed to function as structuring structures... (1990: 5). 
It is from within the habitus then that one learns to live life in a taken-for-granted manner. In the next section we consider in more depth the way in which humans routinise many aspects of daily living, which in turn result in daily mental and social benefits.

\section{The role of habit in agency}

Archer's defence of the increasing importance of reflexivity in agency has also led her to become highly critical of Bourdieu's emphasis on habit in habitus. She rejects the idea that agents engage in any substantial way in routine habitual behavior. Archer, in fact, goes further than this to suggest that attempts to establish the importance of habit over reflexivity or vice versa are ultimately flawed as the discussion has largely been ahistorical. Archer explains: '...habit does, indeed, have a particular place in history - it belongs with morphostasis' (2010: 278).

Bourdieu $(1977,1990,1992)$, in contrast, can be seen as a key advocate of the role of habit in habitus. The two terms are similar sounding, so it is important to be clear about their meanings. Whilst habitus includes an understanding of habit, Bourdieu is insistent that the two concepts are not interchangeable, which leads him to state: "I said habitus so as not to say habit" (Bourdieu and Wacquant 1992: 22). Habitus derives from the latin term "habere" which means "to have" or "to hold" (Fleetwood: 2008). Habit, on the other hand, refers to know how and competence - both mental and corporeal. Bourdieu's intention here is to prevent agency from becoming synonymous with habit, as habit can imply a mechanical response to external rules as can be seen in behavioural psychology's use of the term where it is often interpreted as a biological reflex (Camic: 1986). Bourdieu's other aim in distinguishing between habitus and habit is to stress the 
generative and creative aspects of habitus and action (Bourdieu: 1977).

Action guided by habit is unintentional, pre-conscious, and in a sense 'automatic' - it takes place outside of cognitive awareness or reflexivity. This understanding of habit is supported by cognitive neuroscience that distinguishes habits, or 'automatic cognitive processes' from 'conscious control processes' (Wegner and Bargh: 1998). Routine habitual action is necessary for everyday living and the functioning of the taken-forgranted, in that adherence to habits developed over the life course guide behaviour providing daily reinforcement of routine and often useful habits.

\section{Heuristics and Schematas}

In considering habit, we think it useful to digress for a moment from the main argument of the paper to recognise important insights present in an extensive literature in behavioural and social psychology as well as in Foucault's work (recalling that he also had a background in psychology) on the formation of the self and Kohlberg's work on moral formation. So we will briefly addresses these literatures (keeping in mind that the detail of this literature is beyond the scope of this paper) before underscoring the relevance of these insights to concerns about the viability of Archer's morphogenetic thesis.

Within the extensive literature within psychology, we wish to draw attention to two basic concepts with regards to social learning and the routinisation of everyday life - heuristics and schematas. Heuristics are defined as mental shortcuts (Myers 2008: 90) that the brain uses to minimise the mental space needed to undertake an activity. In learning to 
read, for example, one begins by sounding out individual letters and sounds and in turn to sound out groups of letters and sounds before joining them up into an overall sound that has meaning attached to it. The seemingly unrelated letters of F-R-O-G, which when sounded fluently and connectedly, make the word frog, which in turn is used to refer to four-legged creatures, which live in ponds and dams and make croaking sounds. In one's formative years one learns to dress, tie shoes, walk and talk. One establishes competence in functional activities and as language develops, capacity for emotional competency also emerges (Phillips 1981). There are few if any reasons why one would need or want to relearn such basic competencies unless they were somehow lost, such as in the event of a stroke or a brain injury. The film Regarding Henry starring Harrison Ford (Abrams 1991) provides a vivid description of the challenges an individual faces in re-learning the very taken-for-grantedness of eating, walking and relating to others. As is demonstrated in this film, it is very difficult to transact everyday life if one cannot routinise these many tasks that for most are taken-for-granted. Such routinisation enables one to have confidence in one's ability to do the things that one has come to do. One can be confident that one can, for example, go to work, undertake tasks to the required level of competency, and interact successfully with others such that they are seen to be socially competent. One can regard oneself and others as reliable, trustworthy and so on.

Importantly the social psychology literature notes that individuals develop self-schemas. These can be understood as collections of heuristics which serve as 'mental templates by which we organize our worlds. Our self-schemas - our perceiving ourselves as athletic, overweight, smart or whatever - powerfully affect how we perceive, remember and evaluate other people and ourselves' (Myers 2008: 37). Mentally, individuals routinise 
how they see themselves and ways of interacting with others. Social psychologists report that the medial prefrontal cortex, 'a neuron path located in the cleft between your hemisphere just behind your eyes, seemingly helps stitch together your sense of self' (Myers 2008: 37).

Foucault has provided further illustration of the process of social formation through his concept of technologies of the self $(1988)^{1}$ (as depicted in Figure I below). Within this work Foucault proposed a similar position to Bourdieu in that he saw the socialisation of individuals occurring in a given place at a given time (i.e. in situ). Within such contexts given meanings and symbolism (derived as they have been, often uncritically, from and through the habitus) are deployed through institutions (including families and communities) and their programs, through professionals, parents, teachers and coaches via their various methods and practices and by the individuals themselves who are subject to such processes, who also work to internalise such processes and manifest them in the expression of attitudes and practices. Giddens (1991) took the mastery of such attitudes and skills as a definition as social competence. Foucault does not suggest for a moment that such processes are uncontested or singular; multiple governmental processes may be focused on the individual, albeit that some have greater social salience on individuals than others. Hogan's $(1997,1998,2001)$ work on the socialisation of deafened people provides deep insight into such processes, their contestation and the manner in which they play out in peoples' lives.

1 We note that there are limitations with Foucault's model, not least of which is an absence of insight as to where meaning and symbolism come from and how they are deployed. But these points are an aside to the current paper, and are addressed in forthcoming works by the authors. 
[Insert Figure I here.]

These kinds of processes constantly shape or reinforce the doxic nature of everyday living. They also occur in conjunction with forms of moral and emotional development Kohlberg's (1969) work on moral reasoning being a classic case in point. Within this theory Kohlberg contends that in children's most formative early childhood years, children conform with socialising processes firstly to avoid punishment and then to seek reward (what he refers to as Level I). At Level II (and developmentally mid-to-late primary school) children are morally motivated by external approval, and the desire to avoid rejection or feeling guilty. Adults seek to 'maintain the respect of the impartial spectator judging in terms of community welfare' and at their highest level (Level III), they form their own moral framework, living life by their conscience and acting in a manner to avoid self-condemnation' (Hilgard, Atkinson and Atkinson 1979: 74). Commenting on the work of Kohlberg, Hilgard et al. (1979: 75) observe that 'children develop as moral philosophers who develop moral standards of their own; these standards do not necessarily come from parents or peers but emerge from cognitive interaction of children with their social environment' (1979: 75). For Kohlberg, many individuals do not progress beyond Level II. A distinction in moral reasoning and, therefore, reflexivity is evident. People can and often do reflect about their behaviour and monitor it with regard to ensuring good relations with others, but in Kohlberg's perspective, very few people actually develop an internalised moral value system in which they refer to their own internal standards through which they would guide their own thinking, behaviour and how they see themselves (notably this would equate with Archer's meta-reflexive 
level). Rather, most are focused on avoiding a breach of what others expect of them and will conform how they present themselves in order to ensure they get on with others.

Bringing together these respective insights from psychology we make the point that it is not only basic behaviours that get in from the habitus to form to who we are, our routinised pattern of everyday behaviour, our values and sense of self are also deeply written as it were overtime into how we understand ourselves and act. Deeply written as well is a very strong sense of how others expect us to behave and an awareness (or fear) of the social sanctions for breaching the taken-for-granted, social facts of everyday interactions (see further discussion below). To this end, Archer's notion of morpohogenesis in everyday life is quite problematic because considered in the light of what are diverse, detailed and well received literatures, it simply does not follow that one could so readily and unproblematically re-program the self or to do this in an ongoing fashion. Archer seems to want to pre-figure some kind of self for the post-secular society while ignoring so much of the literature that says for most, such a sense of self is actually achieved by very few people (Daniels, 2015).

Returning then to our main argument, Bourdieu himself insists, agency is much more than just habits or the routinisation of everyday life, as this would lead to the disempowerment of agency, yet habits play an important role in agency as they are one of the portals through which the social gets in. Habits derive from social structures, and they may be learnt through conscious learning, through socialization or through imitation and repetition. Hopf (2010) points out that habits teach us what to do, but also what not to do, such that socially produced absences create social practices that are habitualised 
absences, such as female circumcision. Habits may also be absorbed through everyday practice in a way that avoids a notion of social structure, yet has the same effect. Shove (2003), for example, in her research on conventions of cleaning and comfort suggests that habits are everyday social practices characterized by distinctive forms of regularity and persistence, which often align with our increasing dependence upon technology.

We have then established two critical parts of subjectivity wherein it is unlikely that a person would want to re-think the unthought of - first in the routinisation of the do-able activities of daily living and, second, where going against the unthought of is likely to attract the disapproval of significant others. We are then posed with the challenge to come up with situations in which one would want to, or perhaps be compelled, to usurp the taken-for-granted; to want to let go of the so many routinised things that work for them through their life thus far. And it is here that we bring in the concept of the breach of the taken-for-granted, building as we do on a well-established sociological tradition put forward by scholars in a variety of ways, and ever so succinctly summed up by C. Wright Mills (1959) in his notion of troubles.

Troubles arise when a person can no longer play the game of the social within the public gaze. Their feel for the game fails to work for them perhaps in small ways in some instances and in turn significant ways in others, such that one cannot continue to function in a taken-for-granted manner. It is within the moments when the taken-for-granted becomes salient that one has to consider how and on what basis they will participate in the social and the person may or may not engage in reflexivity as articulated by Archer. Not everyone gets to elect or evaluate all aspects of who they are and whether their form 
of practice readily aligns with the taken-for-granted structuring of everyday social relationships - gender and disability are two instances in which the body itself sets up one in relation to others in a way which can be difficult to manage in a conformative manner - albeit, many try. Moreover, this is a process that does not have to be all or nothing. One can have minor engagements with contestations of identity without having to identify oneself with something other or be identified differently by others. Within such engagements, one does not have to be conscious of the challenges which are confronting identity because, as Akram 2012 has noted, the formation of the taken-forgranted is pre-consciously formed within the habitus. Yet, certain experiences feel uncomfortable, such as what Hétu and Getty (1991) referred to as experiences of misperceptions or experiences of identity contestation. Stigmatisation is being threatened, yet the individual puts the poor experience down to some other thing - such as misperceiving hearing problems as interpersonal conflict. But then there are situations where one's capacity or willingness to maintain the taken-for-granted can no longer be sustained. A woman is so savagely beaten by her husband that she recognises in the window of a moment that her marriage is over. Whilst one can maintain the normalcy of the everyday taken-for-granted way of practice, forays with challenges to identity can be managed, even if personal wellbeing is placed at risk, and the taken-for-granted remains in place.

\section{The breach of the taken-for-granted}


Within the windows of critical moments, however, events unfold in such a fashion that a discontinuity arises in awareness between how one saw the world then, versus now. It is Durkheim's (1984) anomic moment; Nietzsche's nihilism (Warren 1988). And while the taken-for-granted can be ruptured in a moment, the crises into which one is thrust can, as Crossley (2003) notes, last a lifetime. Within a reactive framework, a person can recoil from such moments and attempt to maintain daily practice; but the solution to anomie has to be found in a reflexive process. The only way out of such anomie, as Jung (1963: 19) contends, is to go through a change process. Importantly, the reproduction of discontinuities across time and space (the abuse of women; discrimination against people of difference) evidence the fact that objective, deeply-embedded, social structures exist (what Durkheim $(1984 ; 2002)$ referred to as social facts), irrespective of whether such structures have their basis in the physical, the material or the socially constructed space, or indeed some combination of the three. For Durkheim (1984; 2002), such disruptions to daily practice indicate that social facts are at play. He argued that such facts have an objective reality of their own; they are recognised in the breach, when some socially sanctioned, culturally specific, taken-for-granted, normative way of doing things (such as speaking and replying in everyday communication) is violated, somewhere, at some time.

Similarly, Giddens (1984) argues that this kind of social breach centres on seemingly minor departures from how things are done, trivial in themselves, but imbued with social meaning and expectation. The taken-for-granted, the normative, says Giddens (1984: 2) 'figures as "factual" boundaries of social life'. By its very nature, the taken-for-granted is taken-for-granted! Until, of course, it becomes problematic when a set of social relations or forms of social practice either do not work for groups of people or, for some reason, 
stop working in a way which creates trouble for people at a collective level. The point is that there are social forces that are 'real' in the tangible consequences they have for people in daily life and for life opportunities.

As such the self and self identity are not passively formed by external influences, but that in the presence of existential doubt 'the self, like the broader institutional contexts in which it exists, has to be remade reflexively' (Giddens 1991: 3; also see King 2010). Giddens continues to observe that 'this task has to be accomplished amid a puzzling diversity of options and possibilities'. Central to this challenge is Giddens' notion of trust (or what we later refer to as the predictability of the social), inherently linked as it is to ontological security and thus mental wellbeing. It is this routinisation of the everyday, Giddens argues, that enables one to carve out a space to act. But in carving out such a space, Hogan (1988) shows in his study of deafened people that for the most part people are not so much seeking to carve out a space, but to ensure that they retain their place within existing modes of social relations - a mode of being that asserts their social identity, and their membership of certain family, social groupings and workplaces. That is, in the face of an existing performative identity not working, people seek to re-establish that identity amidst the psychological challenges that ensue. For sure, in the face of such a threat to ontological security, in the face of the ensuing anomie and nihilism, one would think that reflexivity is inevitable. But as the work of Hogan $(2001,1998)$ and Hogan et al. (2012) has shown, for the most part this is simply not the case. At issue is the formation of the taken-for-granted, the doxic nature of the practice of everyday life and social relations and one's place within it - what the social psychology literature refers to as social identity, which is understood as a sense of belonging to a certain group which 
provides emotional and value significance. This can be distinguished from the notion of personal identity, which refers to self-knowledge that derives from the individual's unique attributes (eg. physical appearance) (Haslam 2004: 20).

We contend that any threats to either the personal or social aspects of identity are highly charged emotionally with related physical reactions in the sympathetic nervous system which by their nature, encourage individuals to recoil from going anywhere near the reformation of such identities through fear of significant negative sanctions or marginalisation. Responses to such situations are closely linked with the basic flight/fight responses foundational to human nature. And such that when identity is (even perceived to be) contested, typically in the presentation of self in everyday interactions, one does one's level best to assert one's continuity as a member of specific social groups such as family and friendship groups.

Even when one's capacity to transact such relations is inherently limited, people may still persist with certain behaviours in order to assert their memberships of certain groupings and to avoid rejection and marginalisation (see for example Hétu 1996; Hogan et al. 2012). It is not that one couldn't remake oneself, or learn new skills as Giddens (1991:7) suggests; the question is why would one do such a thing that would inherently alienate oneself from their social? There is of course a way through this labyrinth, as Hogan et al. (2012) demonstrate, yet most people avoid it because of the perceived risks involved. At issue, as Giddens (1991: 8) remarks, is the 'sequestration of experience (which means) that for many people, direct (and we would add emotional) contact with events and situations which link the individual lifespan to broad issues of morality and finitude are 
rare and fleeting'. Giddens argues that it is a sense of shame (tinged as it is with the threat of anomie) or the threat of it, which is at play. Shame, which threatens ontological security to its core, is managed and sustained, primarily 'through the routinisation of everyday life' (1991: 167) as one seeks to enforce one's social identity and legitimate group membership through the exhibition of taken-for-granted, seemingly expected behaviours. Giddens (1991) points out that individuals monitor their behaviour in regard to others and that such monitoring, coupled with reflexivity, is used to smooth off their so called rough edges so that they get on with others better. The framework for this surveillance of the self was birthed in the habitus, which itself is shaped by a multitude of competing and complimentary fields, and which can be readily understood in Foucault's (1998) late work, as noted above.

Prior to a breach, the legitimacy of identity is taken-for-granted. The breach serves as a violation of some socially sanctioned, culturally specific, taken-for-granted, normative way of doing things, occurring somewhere, at some time. But just what does the contestation of ontological security mean for people who hold a specific social identity; how do we theoretically understand such a contestation playing out within identity and a person's subsequent wellbeing? And why do we think that rethinking such a process is a big deal? To answer these questions we look more closely at Gidden's (1991) work on self-identity and modernity.

As Giddens (1984) observes (extending Erikson 1959), the predictability, the trust-ability of the everyday is central to psychological security. Further developing these insights, Hogan (2001) argued that Erikson's eight stages of man in fact make up a matrix of ontological security (see Figure II below) that is dynamic in the face of everyday 
interaction, with ontological security pivoting off the predictability of social identity and certainty in one's capacity for competent social acting within given interactions (Giddens 1984). Hogan (2001) argued that such challenges are not simply contained within developmental life stages (if they are ever so ordered) but are in fact dynamically activated in the face of a challenge to identity on a day-to-day basis. Following Giddens (1984) when one loses confidence (loss of trust in the predictability of the safety of social encounters) in the predictability of everyday life events, in one's place within them and in one's capacity to act competently, a sense of anxiety emerges in the co-presence of the resultant role confusion and its accompanying experience of apparent social incompetence (the breach as it were); one becomes unable to fulfil taken-for-granted social roles. Embarrassment (a form of shame) may result and this can be accompanied by the desire to socially isolate oneself. The cumulative effects of such isolating interactions saps at life's passion, satisfaction with life stagnates and anger and despair can result (see Figure II below).

[Insert Figure II here.]

Giddens (1984: xxiii) argues that the competent execution of the daily routine of social practice, based as it is on the taken-for-granted of everyday activity, is therefore "vital to the psychological mechanisms whereby a sense of trust or ontological security is sustained in the daily activities of social life'. The loss of situational certainty (with its resulting role confusion in the face of contested identity) potentially cascades into experiences of anomie coupled with stress-based responses and subsequent adverse physical and mental health impacts over time (Giddens 1984; Hogan 2001; Hogan et al. 2012). One can swim against the tide as it were and try to sustain identity-based practices 
in the face of contestation, but it comes with the high price of reduced health and wellbeing over time (Cummins et al. 2003). Denzin (1989: 15) tells us, at the individual level, that the breach serves as an epiphanal moment that leaves 'marks on people's lives' and often represents 'a turning point... the person is never quite the same again'.

\section{Reflexivity and the social conditions required for a rethinking of 'the unthought'}

Thus far we have foreseen the need to rethink the unthought of in situations of crisis where such a crisis is seen as a negative. But what of situations which demand a response from the individual with regards to positive social changes, such as the need for men to rethink masculinity in the light of feminism or for able-bodied people to reconsider their attitudes and behaviours in the light of ableism? We address these two concerns in turn.

It comes as no surprise for anyone who has been involved in social movements to note that social change occurs slowly. Moreover, the more deeply written given social practices are within a culture, the more deeply the taken-for-granted nature of practices are, the more beliefs exist at the pre-conscious level, and the less a given culture is exposed to alternate governmental frames, the slower the change process. This is not to say that the habitus is deterministic, but that the extent to which practices are steeped in pre-conscious beliefs, the harder they are to shift quickly. For, as we have illustrated above, such deeply held practices of the everyday are written into social identity and around emotionally charged notions of belonging. The need for reflexivity is contextually 
bound and is mobilised when discontinuities arise amidst practice and the pre-conscious platforms that shape the habitus. Reflexivity and social change in habitus are possible, but, as the account above suggests, change in habitus is difficult. Further, change is not radical change, as, for example, would be involved in removing structural forms of inequality, but refers to small and piecemeal change in one's habitus. This position also implies that the de-traditionalisation thesis, as advocated by Giddens (1991) and Beck (1992), fails to accurately describe processes of reflexivity in society today. Authors such as McNay (1999), Adkins (2003), Sweetman (2003) and Adams (2006), have all, albeit differently, shown in their work that reflexivity is present in habitus whilst also accepting its pre-conscious and pre-reflexive aspects.

The crucial distinction here, and the principle of demarcation from both Archer and the proponents of the de-traditionalisation thesis, is whether reflexivity is a process in which agents can consciously and reflexively orient their identity, and hence lives, or whether identity is seen to be more embedded and, operating on a pre-reflexive and pre-conscious platform. In the absence of breaches or discontinuity we would agree with McNay who argues that habitus suggests a layer of embodied experience that is not readily amenable to self-fashioning because the dispositions of the body operate in a pre-reflexive and preconscious manner outside of the control of the agent (McNay 1999: 102). For McNay then, it is the recognition of the pre-conscious, pre-reflexive, non-cognitive and embodied understanding of practice in Bourdieu's social theory that is central here. But there are several instances where we can see that as a result of gentle but also seismic changes in social identity, the opportunity for change arises. We briefly consider two such examples 
here: the impact of processes of consciousness raising over time, such as is evidenced in the women's and disability movements.

Consciousness-raising (CR) strategies were used by feminists as an approach to raising consciousness about gender inequality. More recently, such strategies are also being developed in the disability field (see for example Hogan et al. et al. 2014 and http://wwda.org.au/). Consciousness here refers to subjective awareness and the experience of knowledge, and by raising consciousness one elevates the importance of that knowledge, bringing to the surface issues that were previously ignored. CR was practiced in feminist meetings which were usually women-only and involved going around a room, where each woman spoke about a pre-determined subject. A typical question was: 'when you think about having a child, would you rather a boy or girl' (Sarahchild 1973). Hogan's work (2001) offered a similar process wherein deaf people were asked to consider the question as to what was the worst thing about being deaf or hearing impaired. The ensuing discussion enabled people to discuss the social impacts of a phono-centric society.

CR strategies present an interesting insight into processes of reflexivity, because they rely on bringing to consciousness those issues which are usually taken-for-granted, exist as doxa or are in the pre-conscious. CR was developed from the principle that gender roles are deeply embedded in society and are regarded as norms of everyday life. As such, CR presupposes the routine characteristics of life that are the subject of this article - it is these aspects of agency that are brought to consciousness and seen to capture forms of inequality in society. With such a view, women's ability to be reflexive about gender is not presumed from the outset, but rather women are encouraged to explore their own 
behaviour and thoughts about gender - the implication being that women are often not aware of their own subjugation and must first recognise it, before they can act to change it.

With differing degrees of intensity, each process contains within it the movement of preconscious, pre-reflexive, non-cognitive and embodied understandings of practice into greater awareness, wherein the process of change opens one up to the possibilities through differing forms of reflexivity.

The position we have put forward so far, using illustrative material from work in feminism and disability activism is that reflexivity comes into play when the taken-forgranted, the doxic nature of everyday living stops working effectively for someone. This can happen completely or partially, but both require responses from the individual. Where one can partially respond, one can possibly adapt one's behaviour so as to be able to conform with more broadly held contentions of the taken-for-granted - passing as a hearing person when one has a serious hearing loss, is a frequently noted example. From the illustrations above, we draw two key points. First, that reflexivity can occur to various degrees, but that it functions in relation to the more enduring features of habitus, such as habits, the taken-for-granted and so on. Second, reflexivity spans a conscious and preconscious space and thus has various intended and unintended effects. Let us expand on these points.

The central argument here is that reflexivity does not replace habit and the taken-forgranted as in Archer's account, but it must operate in relation to them. Because of doxa, the taken-for-granted and pre-conscious platform of habitus, Bourdieu is able to develop 
a much more sophisticated understanding of reflexivity than Archer, one that is based not on an 'objectivist reflexivity', where agents can stand outside of their habitus to be reflexive, but reflexivity understood as 'situated reflexivity' (Adkins 2003: 25). Notably, reflexivity, according to Bourdieu, is not a general capacity available to all agents, but 'paradoxically, is itself a form of habitus, a required constituent of a particular field...' (Adams 2006: 515). Archer rejects hybridising accounts of habitus and reflexivity, yet it is this approach that is implicit in Bourdieu's work.

The argument for increasing reflexivity in society, and an account developed in relation to habitus, is best reflected by Sweetman (2003). Sweetman contends that reflexivity in the habitus is possible because society today is characterised by increased movement between and across social fields. He also claims that reflexivity can result from 'rapid, pervasive and ongoing changes to social fields themselves' (2003: 541). Sweetman advocates a more historically and culturally specific form of reflexivity, arguing that 'contemporary conditions do not simply demand a heightened degree of reflexivity, but may contribute to the development of a particular type of habitus' (2003: 542). Sweetman's position here follows on from Bourdieu's own, when he argues that movement across, and into, new fields may lead to crisis and social change. However, Sweetman suggests that such changes in field-habitus relations are more pervasive in contemporary society, arguing that the disjunction between habitus and field has become a norm, 'a more or less permanent disruption' (2003: 541). However this position simply sets up one of two possible scenarios. One the one hand one persistently pursues the reestablishment of the taken for granted or one's practice fails in the face of such change 
and anomie results. Farmers in western society provide for a fine case study in this instance (see for example Hogan 2012).

Moreover, bringing the insights of Foucault's work to bear on this debate is important, for Foucault showed that there are multiple processes at play in what Bourdieu would call the habitus, with the dominance of specific beliefs and practices emerging as a result of the convergence of interests, which through the exercise of power, were able to give legitimacy to some forms of social practice over others. Frequently such exercises of power were centred on reinforcing taken-for-granted value systems (e.g. a man's world; a hearing world). This then does not mean that there are not counter-discourses at play or that alliances cannot change. Counter-hegemonic views and practices can exist and when specific convergences of interests arise, new beliefs and practices can arise - the convergence of the interests around economy and environment in recent years provide an important case in point.

Bourdieu's account of social change is reiterated by Adkins, who, in fact, goes further to argue that it is the pre-conscious platform of habitus, which enables it to more accurately reflect processes of reflexivity. Adkins concludes,

It is this Bourdesian understanding of practice - as unconscious and pre-reflexive - that has informed the development of a more hermeneutic understanding of reflexivity... reflexivity cannot be understood to concern an objective, cognitive reflection on structure. Indeed reflexivity cannot be understood to be cognitive at all, since knowledge of the world never concerns an external knowing consciousness (2003: 24). 
A limitation of alternative theories of reflexive transformation is that the emphasis on the strategic and conscious processes of self-monitoring overlooks certain, more enduring, reactive aspects of identity (McNay 1999: 103). For example, McNay points to the ways in which men and women have entrenched 'often unconscious investments in conventional images of masculinity and femininity which cannot easily be reshaped' (1999: 103). In addition, she also highlights the fact that, despite women's increased

entry into the labour force, such moves have not freed women from the burden of emotional labour. As McNay claims, the nature of change in gender relations illustrates Bourdieu's claim that habitus continues to operate long after the objective conditions of its emergence have been dislodged (Bourdieu 1990: 13, in McNay 1999: 103). Following McNay, Bourdieu's work on reflexivity and habitus is of value as it demonstrates 'the difficulty of change' (Chambers 2005: 333).

\section{Concluding remarks - juxtaposing Archer's notion of reflexivity with the existing literature}

Having defined Archer's position on reflexivity and agency and considered it in the light of other perspectives, we can now draw together the insights brought out in this paper and present some final views of the debate before us. Recalling Archer's perspective we saw that reflexivity is active in the face of new social and cultural orders which require agents to define their course of social action in novel social situations which can be described as those where ultimate concerns, projects and practices are at issue. We have reviewed social and psychological theory that makes evident the fact that much of everyday life, behaviour and identity are routinised for a variety of reasons, not least of which, one 
could not function physically, let alone emotionally or socially, as an autonomous being if every day one had to re-learn the basic tasks of daily living, which span the range of competencies from putting on one's shoes through to more refined forms of emotional intelligence. The whole debate hangs on what Archer means by novel and ultimate. For sure, if the latter terms refer to anomic or nihilistic experiences, there is no contestation that such experiences may cause one to be reflexive about who they are and how they fit in the world. However, given the weight of existing social and psychological material we have noted above, we think it unlikely that the moral fabric of our societies is so unstable as to require one to confront ontologically demanding situations on a daily or routine basis. Moreover, we note, that with regards to the person's level of moral autonomy, they may readily recoil from the challenges that face them and conform their behaviour to the social requirements put before them.

If, however, Archer is trying to suggest this within a late-modern context, where the essentialities of social value systems have broken down to such an extent that each person has to re-navigate their position of being an ethical individual, then this raises a different issue. Fifty years ago psychologists such as Rogers (1967) and Kolhberg (1969) drew attention to what was required with regards to achieving an internalised form of control and to be able to function as an ethically autonomous self. We would agree that achieving such an integration of selfhood requires deep reflexivity and moral courage, but it is not the kind of thing that one would rework on a daily basis; the cost to self is simply too high. Further, such breaches to ontological continuity simply do not arise that frequently. Similarly, should one reach such a level of moral autonomy, one may reflect on the extent to which one is conforming with one's own moral compass, as Kohlberg (1969) 
has already suggested, but such reflection would for the most part be a matter of a light touch on the structuring of identity and practice in daily life. Notably, such reflection is not essentially social, as Archer suggests, because the individual has adopted their own internalised moral compass, not one that is necessarily centred on societal norms. And in the event that their sense of self and daily practice ran counter to societal norms, such a level of reflexivity would also involve the development of strategies as to how to manage the self in everyday life, as Goffman (1959) also established long ago.

The best that we can draw from Archer then may be a sense of a continuum of light to intense reflexivity which may be counter-balanced against notions of moral selfhood and reactivity, the conforming of the self to the requirements of others. And if this is the case, then Archer has not progressed social theory, but rather relabeled that which already exists in the literature. 


\section{Bibliography}

Abrams, J.J. 1991 Regarding Henry, Hollywood: Paramount Pictures.

Adams, M. 2006 'Hybridizing habitus and reflexivity: Towards an understanding of contemporary identity?', Sociology 40(3): 511-528.

Akram, S. 2012 'Fully Unconscious and Prone to Habit: The Characteristics of Agency in the Structure and Agency Dialectic', Journal for the Theory for Social Behaviour , 43: 45-65.

Akram, S. 2014 A Methodology for Accessing the Pre-conscious: Obstacles to Senior Women's Career Progression, SAGE Cases in Methodology. Sage.

Adkins, L. 2003 'Reflexivity: Freedom or habit of gender?', Theory, Culture and Society 20(21): 21-42.

Archer, M. 1995 Realist social theory: The morphogenetic approach, Cambridge:

Cambridge University Press.

Archer, M. 2000 Being human: The problem of agency, Cambridge: Cambridge

University Press.

Archer, M. 2003 Structure, agency and the internal conversation, Cambridge:

Cambridge University Press.

Archer, M. 2007 Making our way through the world. Human Reflexivity and Social Mobility, New York: CUP.

Archer, M. (ed.) 2010a Conversations about Reflexivity, Abingdon: Routledge.

Archer, M.S. 2010b 'Routine, reflexivity, realism', Sociological Theory, 28(3): 272303.

Archer, M. 2012 The Reflexive Imperative in Late Modernity, New York: CUP.

Beck, U. 1992 Risk society, London: Sage.

Bourdieu, P. 1977 Outline of a theory of practice, Cambridge: Cambridge University Press.

Bourdieu, P. 1990 In other words: Essays towards a reflexive sociology, Stanford, CA:

Stanford University Press.

Bourdieu, P. and Wacquant. L.J.D 1992 An invitation to reflexive sociology, Cambridge: Polity Press.

Camic, C. (1986). The matter of habit. American Journal of Sociology, 91(5), 1039- 
1087.

Chambers, C. 2005 'Masculine Domination, Radical Feminism and Change', Feminist Theory, 6(3): 325-46.

Crossley, N. 2003 'From reproduction to transformation: Social movement fields and the radical habitus', Theory, Culture \& Society, 20(6): 43-68.

Cummins, R.A., Eckersley, R., Pallant, J., Van Vugt, J., and Misajon, R. 2003

'Developing a national index of subjective wellbeing: The Australian Unity Wellbeing Index', Social indicators research, 64(2): 159-190.

Daniels, M. (2015) 'Self-discovery the Jungian way’. The watchword technique.

Routledge Library Editions. $3^{\text {rd }}$ Edition. London.

Denzin, N.K. 1989 'Interpretative Interactionism', Applied Social Research Methods, Vol. 16, London: Sage Publications.

Durkheim, E. (1984) The division of labour in society. New York.

Durkheim, E. (2002). Suicide. Oxford: Routledge and Kegan Paul.

Elder-Vass, D. 2007 'Reconciling Archer and Bourdieu in an emergentist theory of action', Sociological Theory, 25(4): 325-346.

Erikson, E. H. 1959 Identity and the Life Cycle. New York: International Universities Press.

Fleetwood, S. 2008 'Structure, institution, agency, habit, and reflexive deliberation', Journal of Institutional Economics, 4(2): 183-203.

Foucault, M. 1988 'Technologies of the self' in L.H. Martin, H. Gutman and P.H. Hutton (eds) Technologies of the self - A seminar with Michel Foucault, London: Tavistock, 16-49.

Foucault, M. 1991 'Governmentality' in G. Burchell, C. Gordon and P. Miller (eds) The Foucault effect - Studies in Governmentality, London: Harvester Wheatsheaf, 87-104.

Giddens, A. 1984 The constitution of society, Cambridge: Polity Press.

Giddens, A. 1991 Modernity and self-identity. Self and Society in the Late Modern Age, Cambridge: Polity Press.

Goffman, E. 1959. The presentation of self in everyday life. Pengiun Books. Great Britain. 
Haslam, S.A. 2004 Psychology in organisations - the social identity approach, London: Sage Publications.

Hétu, R. 1996. The stigma attached to hearing impairment. Scandinavian Audiology Supplementum, 43, 12-24.

Hétu, R. and Getty, L. 1991. Development of a rehabilitation programme for people affected by occupational hearing loss: 1. A new paradigm. Audiology, 30 (6): 305-316.

Hilgard, R.C. , Atkinson, R. L. and Atkinson, R. (1979). Introduction to Psychology. New York, Harcourt Brace Jovanovich. Inc

Hogan, A. 1997. Issues concerning the governance of deafness. Disability and Society. Vol 12 No. 5: 793-805.

Hogan, A. 1998. Carving out a space to act - acquired impairment and contested identity. Health Vol 2 (1): 75-90.

Hogan, A. 2001. Hearing rehabilitation for deafened adults - a psycho-social approach. London, Wiley (Whurr) Publishers Ltd . 247 pages

Hogan, A., Reynolds, K.J, O’Brien, L. 2012 Towards a Social Psychology of Living With Acquired Hearing Loss.Perspectives. American Speech Language Assocation. http://journals.asha.org/perspectives. Accessed 6 January 2015.

Hogan, A, Phillips, R, Barry, M, \& Duncan, S 2014, A fairer hearing: enhancing the social inclusion of people with hearing loss, University of Canberra Institute for Governance and Policy Analysis and Better Hearing Australia, Canberra.

Hopf, T. (2010). The Logic of Habit in International Relations. European Journal of International Relations, 16(4): 539-561

Jung, C.G. 1963 Memories, dreams, reflections, New York: Random House.

King, A. 2010 'The Odd Couple: Margaret Archer, Anthony Giddens and British Social Theory', The British Journal of Sociology, 61(1): 253-260.

Kohlberg, L. 1969 Stage and sequence: The cognitive-developmental approach to socialization, New York: Rand McNally.

McNay, L. 1999 'Gender, habitus and the field: Pierre Bourdieu and the limits of reflexivity', Theory, Culture and Society, 16(1): 95-116. 
Myers, D.G. 2008 Social Psychology, New York: The McGraw Hill Companies Inc.

Mills, C.W. 1959 The sociological imagination, Harmondsworth: Penguin.

Phillips, J.L. 1981 Piaget's Theory: a primer, United States of America: W.H. Freeman and Company.

Rogers, C. 1967 On becoming a person, United Kingdom: Constable and Company.

Storr, A. 1983 The Essential Jung, New Jersey: Princeton University Press.

Sarachild, K. 1973 ‘Consciousness-Raising: A Radical Weapon’, in Feminist

Revolution, New York: Random House, 144-150

Shove, E. 2003. Converging Conventions of Comfort, Cleanliness and Convenience.

Journal of Consumer Policy, 26 395-418.

Sweetman, P. 2003 'Twenty-first century dis-ease? Habitual reflexivity or the reflexive habitus', The Sociological Review, 51(4): 529-549.

Warren, M. (1988). Nietzsche and political thought. Cambridge: The Massachusetts

Institute of Technology Press.

Wegner D.M, and Bargh J.A . (1998) Control and automaticity in social life. In: Gilbert DL, Fiske ST, andLindzey G (eds) Handbook of Social Psychology. Vol. I. Boston, MA: McGraw-Hill,446496. 


\section{Figures}

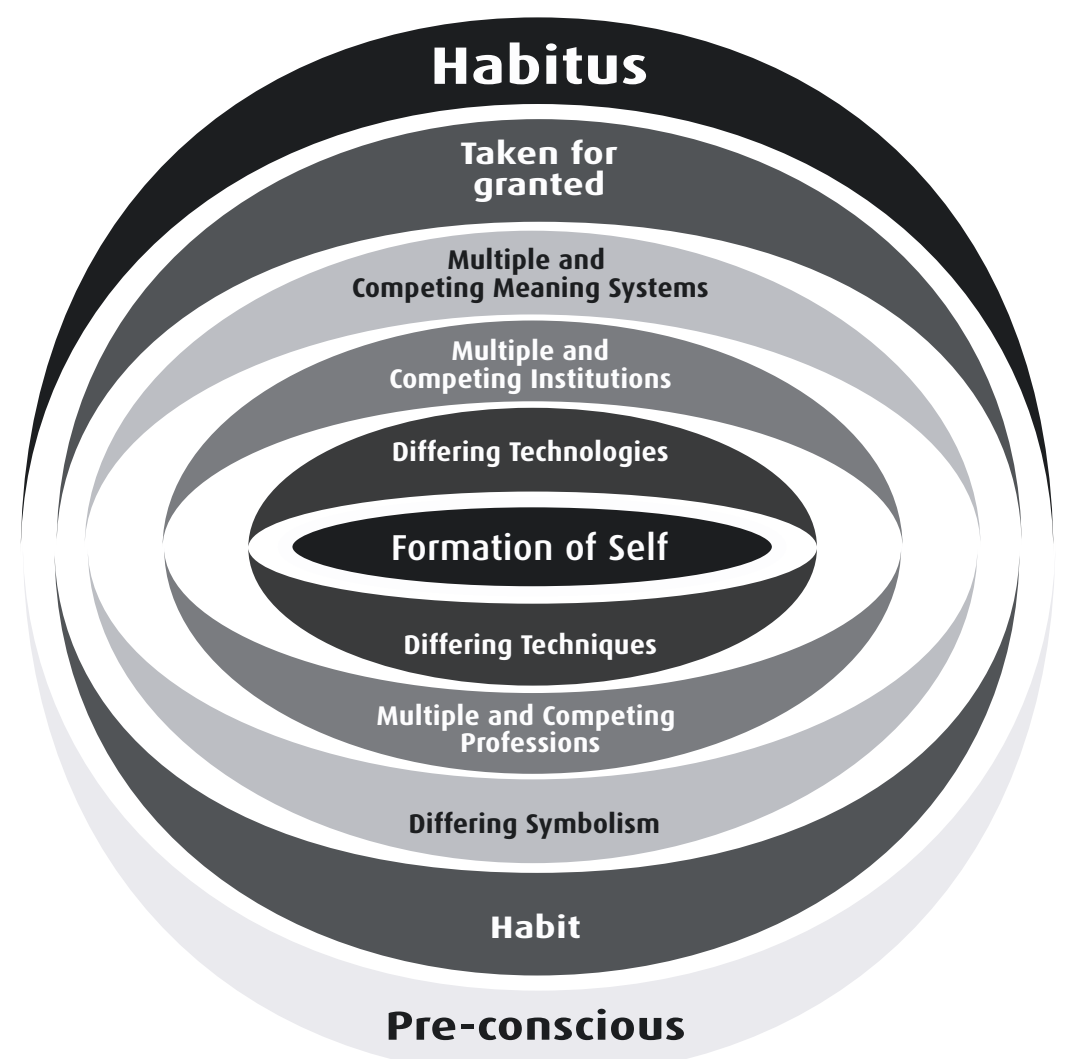

Figure I. Foucault's Technologies of the Self (Adapted from Hogan 2001) 


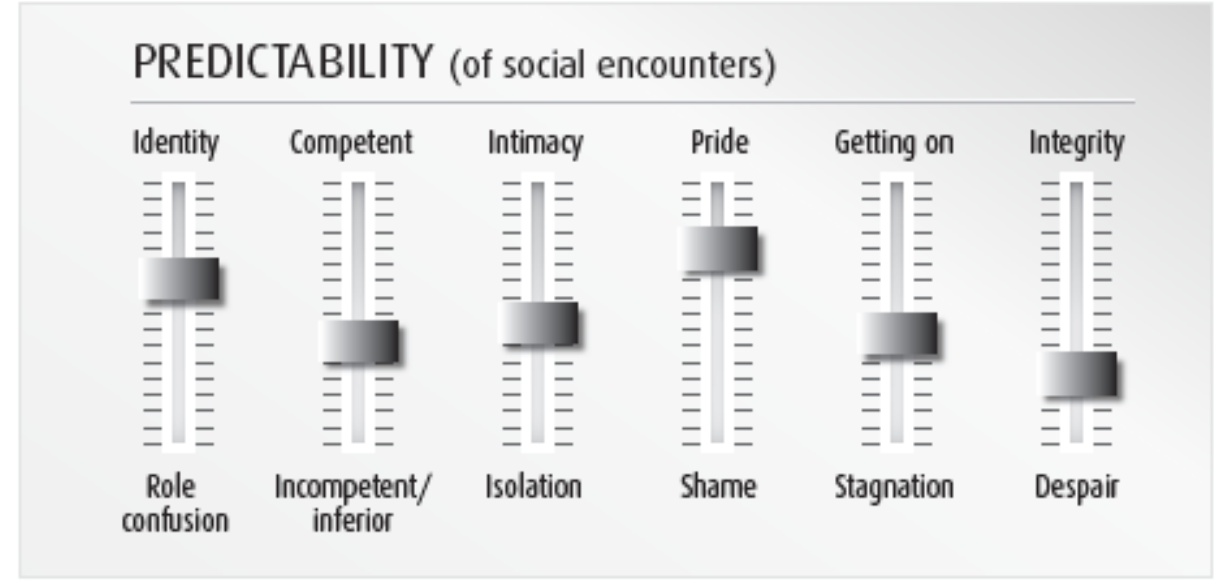

Figure II. Predictability of the social and its impact on psychosocial wellbeing. (Adapted from Hogan 2001) 